\title{
Occupational hazards in hospitals: accidents, radiation, exposure to noxious chemicals, drug addiction and psychic problems, and assault
}

\section{J J GESTAL}

From the Department of Preventive and Social Medicine, Faculty of Medicine, University of Santiago, Santiago de Compostela, Spain

ABSTRACT Except for infectious diseases all the main occupational hazards affecting health workers are reviewed: accidents (explosions, fires, electrical accidents, and other sources of injury); $;$ radiation (stochastic and non-stochastic effects, protective measures, and personnel most at risk); ${ }_{\overrightarrow{0}}^{\circ}$ exposure to noxious chemicals, whose effects may be either local (allergic eczema) or generalised ${ }_{\circ}^{\circ}$ (cancer, mutations), particular attention being paid to the hazards presented by formol, ethylene ${ }^{\supset}$ oxide, cytostatics, and anaesthetic gases; drug addiction (which is more common among health workers than the general population) and psychic problems associated with promotion, shift work and emotional stress; and assault (various types of assault suffered by health workers, its causes, and the characterisation of the most aggresive patients).

In a previous paper attention was drawn to the current importance of occupational hazards to hospital workers. ${ }^{1}$ These were classified into six categories (infection, accidents, radiation, exposure to noxious chemicals, drug addiction and psychic problems, and assault), and the risk of infection was discussed. In the present paper the remaining categories are considered.

\section{Accidents}

Among the possible types of accidents are included fires, explosions, electrocution, and gas leaks; undesired effects of electromagnetic fields, microwaves, lasers, and vibration; cuts, bruises, and fractures; asphyxia and burns; and the effects of noise.

\section{EXPLOSIONS}

Explosions usually occur in laboratories, operating theatres, and boiler rooms. All products that are inflammable or otherwise likely to explode should be labelled as such and stored accordingly. ${ }^{2}$

FIRE

Official regulations concerning the risk of fire in hospitals are in general adequate. Each centre should draw up fire procedures and all hospital workers

Accepted 5 August 1986 should be instructed as to what to do in case of fire. Of 300 fires in United States hospitals, $74 \%$ were due to the following four causes, human error being ulti-o mately responsible in almost all cases: electrical faultso $(23 \%)$, cigarettes and matches $(21 \%)$, incorrect use of anaesthetics, oxygen, and inflammable fluids $(19 \%), \overrightarrow{\overrightarrow{0}}$ and non-electrical heating (11\%).

The most common direct cause of casualties associ ated with inospital fires is asphyxia by smoke and? fumes, which accounts for $78 \%$ of deaths and $43 \%$ of non-fatal casualties. $^{3}$ Fire prevention measures should aim to achieve four main objectives in cases of fire: immediate detection, rapid extinction or iso lation, non-propagation of smoke and fumes, and safe evacuation of staff and inmates. To these ends attention should be paid to four basic points:

(1) Construction-for example, evacuation routes and fire escapes.

(2) Use of combustible materials such as plastics or inflammable fluids.

(3) Countermeasures, including compulsory instal lation of fire extinguishers.

(4) Training of personnel.

The hospital's fire procedures should be familiar to all staff so that they all know exactly what to do in case of fire. Fire procedures should furthermore bef? reviewed at least every six months and corrected as necessary, and fire drill should be practised in alb shifts. ${ }^{4}$ 
ELECTRICAL ACCIDENTS

Electrical accidents may cause injury both directly, due to the passage of electric current through the body producing electrocution, internal and external burns, or gaseous embolism; and indirectly, in the form of burns or asphyxia produced by electrical fires or explosions, or injuries suffered in falls after electric shock. The immediate physiological effects of electric shocks depend on the intensity of the current borne, the point of contact, and the path taken through the body. Currents near the threshold of perception $(1-3 \mathrm{~mA})$ are innocuous even when there is prolonged contact, but as the intensity of the current rises the tingling sensation becomes progressively more unpleasant. Sudden application of $8 \mathrm{~mA}$ generally stimulates a reflex response which may itself bring about injury - due, for example, to a consequent fall off a ladder-but electrification by currents of this magnitude does not normally have direct physiological consequences. Currents greater than about $10 \mathrm{~mA}$ produce muscular contractions that lock the hands and arms and prevent the release of the objects held. Burns may also appear. When the current borne is of more than 25-30 mA, spasm may affect the muscles of the thorax and cause "asphyxia" if artificial respiration is not rapidly applied.

Electric shock may be fatal if the current passes through the brain or the thorax, especially if the heart is affected. Since electric current takes the path of least resistance, particular danger thus attends double contacts in which the body forms a bridge between a live wire and a conductor (right hand and left foot or vice versa, right and left hands, or hand and head). Double contacts affecting a single limb are less serious.

There are two contributions to the electrical resistance of the human body: the external resistance of the surface at which contact is made and the resistance of internal tissues. The external resistance varies from one individual to another and from one part of the body to another (a calloused palm is much more resistive than the back of the same hand), and also depends greatly on the humidity of the surface (due, for example, to sweating: more than $60 \%$ of electrical accidents suffered by hospital personnel occur during the hottest five months). A skin with a resistance of several hundred thousand ohms when dry may offer just 1000 ohms resistance or less when wet. The resistance of the area of contact also decreases as the contact pressure increases. The resistance of internal tissues varies less and is estimated at between 100 and 5000 ohms.

The chief electrical hazard in hospitals is the large static charge that may accumulate in electrical apparatus. Arcing may occur between charged material and neighbouring conductors, and the human body may receive electric discharges if insulated from earth by rubber soled footwear. In fact, if the atmosphere is dry just walking about on asphalt flooring, or even on a woollen carpet, can charge the body sufficiently as to produce small sparks that, though not normally harmful in themselves, may ignite inflammable vapours and gases, cause dust explosions, or (more commonly) startle the person in question so that other types of accidents occur. An idea of the risk of sparking may be given by the fact that an insulated human body dressed in nylon overalls can easily acquire up to 5 or $10 \mathrm{~mJ}$ of electrostatic energy just by sitting down on a chair covered in polyvinyl chloride and getting up again.

The control of electrostatic charge is difficult and generally entails facilitating its loss. In the case of the human body both footwear and flooring should be sufficiently conductive as to prevent the accumulation of charge. Flooring should be of wood, footwear of antistatic rubber, and polyester or polyamide clothing should be worn. The risk of sparking may also be reduced by increasing the humidity of the air and by wearing clothing with antistatic coatings (although most of the latter are lost in the wash, some have appeared in recent years which are relatively permanent). As regards other types of electrical accident, apart from the instruction of personnel in the proper use of electricity and the frequent periodic maintenance of apparatus and mains wiring, the measures to be taken to minimise risk include the earthing of all apparatus, the installation of circuit breakers, the use of low mains voltages, and the separation of mains circuits. $^{5}$

\section{CUTS, BRUISES, AND FRACTURES}

Cuts, bruises, and fractures may occur in hospital work just as in any other human activity. DominguezCarmona, for example, mentions the case of a nursing nun who was killed in 1976 in the Hospital Clínico, Madrid, when a lift she was entering started up on being called from a higher floor, the second fatal accident of this type in the centre in question. ${ }^{6}$ The risk of accident is greatly increased by physical fatigue, which is common towards the end of the day's work but varies in intensity from one department to another and also depends on the building in which the department is housed and the type of personnel concerned. In old fashioned buildings it may be necessary to do a lot of walking from place to place, and even in well designed hospitals nurses spend most of the day on their feet, with the consequent prevalence of varicose veins and foot complaints. Long working hours, changes of shift, and the arrangements before such changes, eating hours, and coffee or tea breaks, and free time and holidays all greatly affect the fatigue and general health of nursing staff. Training and 
qualifications nevertheless reduce the risk of accidents: a survey carried out in the United States showed that nurses who had received a diploma suffered fewer injuries than less qualified nursing staff. Among nurses with a diploma about $30 \%$ of all accidents were due to overeffort and $20 \%$ to falls. ${ }^{7}$ Accidents due to overeffort when lifting heavy weights, however, are far from being restricted to hospital nurses; domestic nurses being quite as much at risk, if not more. The risk of accidents from falling objects, burns, machines, beds, operating tables, glassware, needles, or scalpels is similar to that encountered in other occupations in which comparable equipment is used.

The nature of dental work exposes dentists to a special set of hazards. The use of pointed metal instruments carries a risk of pricks and cuts (which may also be caused by the edges of gold or steel crowns) and of face and eye wounds caused by fragments of tooth or metal when drilling. In the past, painful and deforming cervical, dorsal, and lumbar complaints were also frequent as the result of the dentist spending all day on foot leaning over the chair. Modern workposts have largely solved this problem by allowing the patient to be positioned so that the dentist may work comfortably while seated or standing.

\section{NOISE}

Noise constitutes an increasing problem in hospitals and clinics as elsewhere. No cases have been reported in dentists in which actual loss of hearing may be attributed to the use of low, medium, or high speed drills, though the latter are extremely noisy ${ }^{7}$; but it is less clear whether the noise made by drills may not give rise to psychological problems such as loss of concentration, character changes, or irritability. ${ }^{7}$ Other health workers likely to be exposed to high noise levels produced by certain of the machines they work with include traumatologists, orthopaedic surgeons, and ear, nose, and throat specialists. ${ }^{8}$ The harmfulness of noise depends not only on the characteristics of the noise itself (its intensity and cadence) ${ }^{9}$ and those of the place in which the noise is experienced but also on the susceptibility of the exposed subject, ${ }^{10-15}$ many cases of acoustic trauma having been reported in which the noise level was not particularly high. ${ }^{1617}$ It should also be remembered that quite soft noises of certain types may be extremely unpleasant and their continual repetition may constitute a long term psychic health hazard. In the United States the recommended maximum noise levels for hospital wards are $45 \mathrm{~dB}(\mathrm{~A})$ during the day and $35 \mathrm{~dB}$ (A) at night. ${ }^{18}$ Hospital rooms should be suitably sound proofed, noisy faults in taps, cisterns, trolleys, and so on should be repaired as quickly as possible, soft soled footwear should be worn, and medical sys- $\frac{3}{2}$ tem alarms and telephones should be muffled. Other $\stackrel{?}{?}$ suggested measures for limiting noise levels in hospitals include restrictions on conversations between $\stackrel{5}{+}$ staff and patients with hearing difficulties and the isolation of noisy patients. ${ }^{19}$

There have been several studies of the economic $\frac{\bar{m}}{5}$ effects of accidents in various Spanish hospitals. ${ }^{20-23} \stackrel{\varnothing}{\unrhd}$ R Fernández-Crehuet estimated that in the five years 1978-82 the working days lost through accident in the Hospital "Reina Sofia" in Cordoba cost 16117629 . pesetas (about £80,600).

\section{Radiation}

Serious hazards are presented to health workers by + the medical use of ionising radiation. The radiation to 0 which hospital staff may be exposed includes both $r$ photonic radiation ( $x$ rays and $\gamma$ rays) and charged particle radiation ( $\alpha$ and $\beta$ rays).

$x$ Rays are generated by conventional radio- $\rightarrow$ diagnostic and $x$ ray therapy equipment and by high energy $x$ ray tubes. Gamma rays are produced by cobalt and caesium bombs and by radioelements $\stackrel{\oplus}{\rightarrow}$ encapsulated in needles, tubes, or pearls, which may $\vec{\varphi}$ also emit $\beta$ rays. Finally, unencapsulated radio- $\underset{\vee}{\infty}$ elements are used in solutions or colloidal suspensions administered to patients and laboratory animals or applied in radionuclear laboratories to biological material obtained from patients or ani-

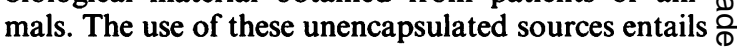
the risk of laboratory equipment, workspaces, and $\triangle$ personnel becoming contaminated. 2425

\section{IONISING RADIATION}

The effects of exposure to ionising radiation appear sooner or later after a latency period and may be either stochastic or non-stochastic. Most of the cases $\stackrel{\mathbb{}}{\exists}$ mentioned in textbooks of radiobiology involve either 0 massive exposure to radiation used for military purposes or doses of the same order of magnitude as $\delta$ those administered to patients subjected to radio- 3 therapy. Personnel working in properly constructed 은 centres should never be exposed to such large doses so long as they observe the necessary precautions, ${ }^{25}$ but many health workers are none the less the object of

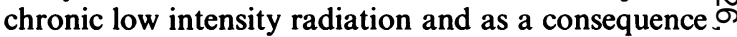
a small percentage may suffer somatic and genetic sto- $N$ chastic effects and possibly certain non-stochastic $\mathrm{N}_{\mathrm{W}}$ effects also. In 1959 it was reported that there had been 359 deaths from radiological causes throughout the world.

\section{Non-stochastic somatic effects}

Non-stochastic somatic effects may arise in the haematopoietic system, with occasional hypoplasia or 
even aplasia, and yearly or half yearly analyses of peripheral blood should be carried out to check for this condition. Dermatological effects may include brittle, cracked, or grooved nails, the disappearance of body hair and fingerprints, and chronic radiodermitis. Cataracts may develop. Irradiation of embryos or intrauterine fetuses by doses of more than 1 rem may cause abortion, fetal death, or the serious malformation of those fetuses that complete their gestation. Alterations may also be produced by unencapsulated radioisotopes able to cross the placental barrier.

\section{Stochastic effects}

Stochastic effects include the shortening of life, the induction of cancer and leukaemia, and genetic effects (an increase in the frequency of mutations). ${ }^{26} 27$

Nowadays, the main radiation hazard occurs not in hospital radiological departments ${ }^{28-30}$ but in the consulting surgeries of general practitioners and small private clinics where adequate safety measures have not been put into effect, and in hospital departments other than the radiological department that may also have occasion to use radiation (operating theatres and casualty and paediatric departments, for example). Professional radiological staff are also less likely to expose themselves to radiation than other personnel such as casualty staff or paediatricians, among whom cases of radiodermitis and skin cancer still sometimes occur. The most dangerous operations for these workers include radioscopy and the use of $x$ ray surveillance of the setting of fractures, searches for foreign bodies, and the introduction of catheters.

\section{NON-IONISING RADIATION}

Theoretically, non-ionising radiation used in hospitals may also constitute a health hazard. Such radiation includes ultraviolet light, laser beams, magnetic fields, and radiofrequencies. Ophthalmologists who work many hours a week with lasers have been reported to suffer from reduced central visual acuity, abnormal colour perception, and other defects indicative of possible macular damage, ${ }^{31}$ and although these claims have not been confirmed, various bodies have established norms for the use of laser equipment. ${ }^{32-34}$ Monitor screens have been blamed for eye strain, postural complaints, and psychological alterations leading to "technostress."35-42 In general, however, the risk of health problems derived from non-ionising radiations is negligible. Perhaps the only individuals clearly put at risk by a subclass of radiations of this type are those who have had pacemakers implanted, since exposure to strong magnetic fields such as those used in nuclear magnetic resonance equipment will probably disrupt the timing of the pulses generated by the pacemaker.

\section{Exposure to noxious chemicals}

Many of the hazards faced by hospital staff consist in the wide variety of chemical substances used. Apart from cutaneous infections, dermatological effects of other infectious diseases, and infestation by parasites, and leaving aside the now quite rare occurrence of radiodermitis discussed above, the cutaneous occupational diseases suffered by hospital workers may be classified as either irritations (caused by chemical disinfectants and detergents) or allergies (caused, for example, by antibiotics, rubber, nickel, disinfectants, aldehydes, or phenothiazines). The occupational origin of dermatosis may be ascertained on the basis of the shape of the area affected, its distribution and location, the recurrent coincidence in time with particular occupations, the patch test, and the response to treatment. Skin complaints make up half the total number of occupational illnesses both among hospital workers and among the working population in general, $90 \%$ of them being cases of contact dermatitis. Some $60-80 \%$ of these cases are caused by chemical irritants (eczema due to primary irritants) and the remainder are of an allergic nature (allergic eczema).

Occupational allergic eczema is more common among nurses, surgical assistants, and other auxiliaries than among doctors because of their continual contacts with drugs, anaesthetics, and antiseptics. Resistance is reduced by repeated washing with soap and, especially, by scrubbing the hands and forearms, which destroys the skin's protective layer of fatty acids. Surgical and casualty personnel may suffer from "dry hand syndrome" due to handling plaster of Paris. Dentists and dental technicians are often affected by contact eczema caused by handling acrylic monomers, local anaesthetics, essential oils, dental mould paste, epoxy resins, and amalgams. Laboratory personnel are likewise put at risk by many of the chemicals they handle. ${ }^{43-47}$

Mutagenic or carcinogenic effects result from many substances used or found in hospitals. Thus betapropiolactone is known to be carcinogenic ${ }^{48-50}$; hexachlorophene is neurotoxic when applied to the skin, as was illustrated by the neural degeneration suffered some years ago by French infants to whom it was applied in talc, and its teratogenic effects in people are also currently being investigated ${ }^{51-53}$; sodium orthophenylphenate and glycols have been responsible for cancer of the bladder; and benzol (and xylol, toluene, and xylene contaminated with benzol ${ }^{5455}$ ) produces leukaemia and chromosomic aberrations. Busch and Nelson have reported cases of acute respiratory distress in histological laboratory staff exposed to xylene, ${ }^{56}$ which may also give rise to headaches, nausea, loss of appetite, lassitude, and 
impaired coordination. ${ }^{57}$

FOR MOL

Since 1894 formol has been used for terminal disinfection of hospital rooms, beds, and apparatus. It is also used as a preserving agent in pathological anatomy and in the preparation of Salk and hepatitis B vaccines. Apart from these medical uses of formol in hospitals, ${ }^{58-62}$ there are also non-medical sources, including chipboard and plywood, carpet glues, parquet varnishes, and urea-formol foam plastics used as thermal insulators. ${ }^{63-70}$ The emanation of formaldehyde from these materials depends on the temperature, the humidity, the age of the materials, and the technical quality of the products. ${ }^{68-71} \mathrm{~A}$ volume concentration of $40 \mathrm{ppm}$ of formaldehyde is also contained in tobacco smoke,,$^{72-74}$ and an individual smoking 20 cigarettes a day may retain some $0.38 \mathrm{mg}$.

Uptake of formaldehyde occurs chiefly through the digestive and respiratory systems, absorption through the skin being negligible. ${ }^{75}$ Small quantities are normal in the cell. Its half life in the blood is about one and a half minutes.

In recent years several comprehensive reviews of the toxicity of formaldehyde have appeared. ${ }^{76-79}$ The main effect of exposure to low concentrations is to irritate the eyes and the upper respiratory tract, ${ }^{80-85}$ though other parts of the respiratory system and the skin may also become sensitised. ${ }^{86-88} \mathrm{~A}$ concentration of $10 \mathrm{ppm}$ begins to be unbearable, giving rise to burns in the nose, trachea, and eyes accompanied by intense lacrimation, coughing, palpitations, and a sensation of thoracic and cephalic oppression. Concentrations of $50-100 \mathrm{ppm}$ produce pulmonary inflammation and oedema and ultimately death. ${ }^{89}$

The North American Contact Dermatitis Group have ranked formaldehyde as tenth in a list of those chemicals causing most skin reactions. ${ }^{90}$ Allergic dermatitis caused by contact with formaldehyde has been found in the medical sphere among nurses handling thermometers sterilised in $100 \mathrm{~g} / \mathrm{l}$ formaldehyde solution, ${ }^{91}$ personnel using disinfectants containing formaldehyde, ${ }^{92}$ and patients whose injuries have been dressed with plaster impregnated bandages containing $100 \mathrm{~g} / \mathrm{l}$ of melamine formaldehyde resin..$^{9394} \mathrm{In}$ 1966 Blejer and Miller described an outbreak of contact eczema in a haemodialysis unit where a $20 \mathrm{~g} / 1$ solution of formol was used to sterilise open tanks. ${ }^{95}$ Specific sensitisation of the respiratory tract is also possible, though this is much less common than sensitisation of the skin..$^{9697}$ In recent years the automating of sterilisation processes, better ventilation, and greater awareness of the need to use protective systems has reduced the incidence of such cases. ${ }^{98} \mathbf{9 9}$

Formaldehyde is known to be highly reactive with nucleic acids and proteins, ${ }^{100-102}$ and several studies have shown its mutagenic effects on various micro-

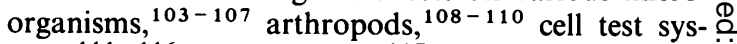
tems, ${ }^{111-116}$ and mammals. ${ }^{117}$ Since squamous cell $\vec{\Rightarrow}$ carcinomas of the nasal passages of rats and mice $\stackrel{\oplus}{\stackrel{9}{+}}$ exposed to 6-15 ppm of formaldehyde were observed 을 in the United States, ${ }^{118-120}$ there has been contro- 음 versy world wide as to whether formaldehyde is or is $\frac{\bar{\sigma}}{7}$ not carcinogenic, ${ }^{121-124}$ and there have been numer- $\stackrel{\mathbb{Q}}{\Omega}$ ous studies of morbidity ${ }^{125}$ and mortality ${ }^{126-135} \mathrm{~N}$ among groups of workers subject to occupational $\vec{A}$ exposure to formaldehyde. No abnormally high rates of mortality from nose or lung cancer have been $\vec{\omega}$ observed in these groups, but there have been reports $\stackrel{\vec{D}}{\circ}$ of higher than average mortality from tumours of the $\stackrel{\triangleright}{\mathbb{D}}$ prostate, skin, kidney, brain, mouth, colon, bladder, $?$ and bone, and from leukaemia. Most of these studies are open to the criticism that the small number of $\infty$ subjects prevented significant conclusions being reached-for example, in the case of nose cancerbut a much larger study has recently been carried out by Acheson et al, who found no evidence of higher $\rightarrow$ than average rates of mortality from any of the tumours mentioned in earlier studies (including nose cancer) and concluded that formaldehyde is not car- $\stackrel{\oplus}{+}$ cinogenic in man. ${ }^{136}$ Further research on this subject $\vec{\oplus}$ is nevertheless still needed before definitive conclu- $\stackrel{\infty}{-\infty}$ sions can be arrived at.

The attitude of official bodies to formaldehyde has exhibited the same incoherence as scientific publications. In 1981 the National Institute for Occupational Safety and Health declared formaldehyde to be a possible carcinogen, ${ }^{137}$ and in April 1982 the United States Consumer Products Safety Commission responded to numerous com- $\exists$ plaints regarding the irritant effects of formaldehyde in the respiratory tract and its possible carcinogenic potential by banning the use of urea-formol foams as insulators in the building trade. ${ }^{138} \mathrm{~A}$ year later the ban was lifted by the Court of Appeal on the grounds of the incorrectness of the documentation presented 3 by the CPSC regarding evidence of the health hazard 8 posed by the chemicals given off by the foams. ${ }^{139}$ In May 1984 the Environmental Protection Agency nev- 을 ertheless included among its priorities reviewal of the use of urea-formol resins in housing. ${ }^{140}$ Similar situations have been created in other countries. A World Health Organisation working party recently recom- $O$ mended that because of its possible carcinogenic $N$ effects, formaldehyde concentrations at work should be reduced as much as possible, and that as a provisional limit workers should in any case not be exposed to concentrations in the air of more than 0.5 $\mathrm{mg} / \mathrm{m}^{3}$ for a mean eight hours a day in a working week of 40 hours. $^{76}$

ETHYLENE OXIDE
The bactericidal properties of this colourless gas were 
first made known in $1929,{ }^{141}$ and since 1962 it has been widely used to sterilise medical material. At present it is the disinfectant gas most widely used to sterilise plastics and other materials that cannot be subjected to heat. Its acting at room temperature also makes it economical. Its disadvantages, however, include its being explosive, which makes it necessary to mix it with inert gases; its remaining impregnated in the material being sterilised (it dissolves in rubber), which means that the material sterilised must subsequently be ventilated; and its toxicity, concentrations of $50000-100000 \mathrm{ppm}$ being lethal in a few minutes. ${ }^{142}$

In the United States more than 2000 million kilos of ethylene oxide are produced yearly. Although less than $1 \%$ of this total production is used for industrial or medical sterilisation, this use constitutes the greatest health hazard, with an estimated 100000 health workers at risk in the sterilisation services of United States hospitals. Whereas other industrial applications use ethylene oxide in closed circuits or outdoors, sterilisation involves open processes carried out in closed premises. ${ }^{143}$.The areas of greatest risk are in general the sites where ethylene oxide chambers are emptied, the most dangerous moment being when the door is opened.

Exposure to ethylene oxide, usually either contact with the skin or inhalation, may produce either local or generalised effects. The exposed individual's defensive reactions are hampered by the typical lag of several hours between exposure and the appearance of symptoms, and by the fact that the gas is imperceptible to smell until quite high concentrations are present $(700 \mathrm{ppm}){ }^{144}$ Contact with insufficiently ventilated materials containing ethylene oxide (such as gloves, face masks, overalls, tampons, endotracheal tubes, or anaesthetic masks) produces irritant cutaneous lesions, ${ }^{145-.149}$ conjunctivitis and corneal burns, ${ }^{150}$ and, after exposure to high concentrations, cataracts. ${ }^{151-153}$ Repeated contact may give rise to allergic sensitisation. ${ }^{154}$ Generalised effects may include acute poisoning, the seriousness depending on the intensity of exposure. Mild symptoms include nausea and vomiting ${ }^{155}$ and irritation of the eyes, nose, and throat, whereas in the more serious cases there may be respiratory problems (dyspnoea, cyanosis, and pulmonary oedema), which may be produced by just a few minutes exposure to concentrations of $500-700 \mathrm{ppm} .{ }^{144}$ Other symptoms may affect the heart, the nervous system (with headaches, sleepiness, weakness, lack of coordination, and convulsions), ${ }^{144}$ the blood $^{156}$ and anaphylaxis. ${ }^{157}$ Chronic ethylene oxide poisoning may cause encephalopathy, polyneuritis, and neurovegetative lesions. ${ }^{158}$ Exposure during gestation has been reported to induce premature deliveries ${ }^{144}$ or abor- tions. ${ }^{159}$

There are no data suggesting that ethylene oxide has teratogenic effects in man, and the results obtained with laboratory animals are contradictory. ${ }^{160161}$ As an alkylating agent, ${ }^{162}$ many studies have confirmed its mutagenic action in microorganisms, ${ }^{163}$ arthropods, ${ }^{164}$ plants, ${ }^{165166}$ and the cells of $\operatorname{man}^{167168}$ and other mammals. ${ }^{169170}$ The frequency of chromosomic and chromatinic anomalies in lymphocytes is also known to be higher among people chronically exposed to ethylene oxide than among the general population. ${ }^{171-175}$ Rats exposed to ethylene oxide atmospheres have been observed to suffer from leukaemia and mesothelioma, ${ }^{171}$ and subcutaneous innoculation in mice increases the incidence of fibrosarcomas. ${ }^{176}$ The epidemiological studies conducted among people are nevertheless insufficient to enable definitive conclusions regarding its possible carcinogenic action, for whereas Hogstedt et al $\mathbf{1}^{177178}$ reported an increase in both general mortality and mortality from tumours (especially leukaemias), a study carried out in the United States found no such effect. ${ }^{179}$ Uncertainty regarding the duration and intensity of exposure hinders the drawing of conclusions, and further epidemiological studies are required.

The degree to which an individual has been exposed to ethylene oxide may be measured biologically by its alkylating haemoglobin and binding to histidine to give N-3(2-hydroxyethyl) histidine. ${ }^{180}$ Legally established tolerable limits vary from one country to another. In 1971 the American Conference of Governmental Industrial Hygienists proposed 50 ppm as the mean allowable concentration in the workplace, ${ }^{181}$ but information gathered concerning mutagenic and possible carcinogenic effects has led to a legal threshold limit value (TLV) of $10 \mathrm{ppm}$ and a proposal in 1982 for a reduction to $1 \mathrm{ppm},{ }^{143}$ the same level proposed in 1983 by the Occupational and Safety Health Administration. ${ }^{182}$ In the USSR the limit is $0.5 \mathrm{ppm}$. After comparing the alkylating and mutagenic potential of ethylene oxide with that of ionising radiation, Calleman et al proposed a TLV of $0.25 \mathrm{ppm}$, which would be equivalent to the maximum allowed dose of 5 rads of radiation a year. ${ }^{180}$

In the light of the data now available, it may be concluded that whenever possible sterilisation by ethylene oxide should be replaced by sterilisation by $\gamma$ rays or propyl oxide.

\section{CYTOSTATICS}

Certain oncolytic agents have long been known to produce contact dermatitis and blisters, and elementary precautions have always been taken to avoid their contact with the skin of the patients to whom they are administered and the nurses responsible for 
their administration. Modern studies, however, have shown that the mutagenic hazard presented by cytostatics (found by Hoffman ${ }^{183}$ in the urine of nurses and technicians who had prepared or administered antitumour agents) is not limited to physical contact but also includes the inhalation of vapours and microdroplets given off during the preparation and administration of cytostatic solutions, and these mutagenic effects are reinforced by smoking. Immunological alterations have been observed in the lymphocytes of the peripheral blood of both patients treated with cytostatics and the staff who had prepared and administered the drugs. ${ }^{184-187}$ To eliminate these risks, cytostatics should be prepared and reconstituted in vertical laminar flow chambers using a laboratory coat, gloves, and a face mask, and the same rules should apply to the handling of the urine of patients treated with these substances. ${ }^{188-190}$

\section{ANAESTHETIC GASES}

The first reports of harmful effects of anaesthetic gases among health workers are those of Hewitt (1893), Kirschner, ${ }^{191}$ and Perthes (1925), ${ }^{192}$ all of whom described acute effects. Hirsch and Kappurs soon pointed out that although acute poisoning is infrequent, the likelihood of chronic poisoning cannot be neglected, ${ }^{193}$ and cases of chronic poisoning were described by Werthmann in $1948 .{ }^{194}$ Nevertheless, this problem was generally ignored until in 1967 Vaisman carried out an epidemiological study of Soviet anaesthetists, ${ }^{195}$ since when a variety of disorders have been attributed to anaesthetic gases. ${ }^{196-198}$ Following Cascorbi, ${ }^{199}$ we shall classify them into three main groups: changes in behaviour and the ability to perform psychometric tests, diseases of the organs for the biotransformation and excretion of xenobiotics, and faulty cell replication.

\section{Changes in behaviour and the ability to perform psychometric tests}

Bruce et al found that volunteers exposed to trace concentrations of anaesthetic gases $(50-500 \mathrm{ppm}$ of $\mathrm{N}_{2} \mathrm{O}$ with or without 1,10 , or $15 \mathrm{ppm}$ of halothane) suffered alterations of perception, cognition, and motor skills. ${ }^{200-202}$ Neither Smith and Shirley, ${ }^{203}$ nor Frankhuizen et al, ${ }^{204}$ nor Venables et al, ${ }^{205}$ however, have been able to reproduce their results, which are furthermore questionable as regards their statistical significance ${ }^{197}$ and the surprising finding that nitrous oxide alone was more deleterious than when accompanied by halothane. ${ }^{202}$ Occupational exposure to traces of anaesthetic gases has not been observed to give rise to neuropsychiatric disorders. ${ }^{206-208}$ Quimby et al found that rats exposed to $10 \mathrm{ppm}$ of halothane for eight hours a day, five days a week from birth to the age of 60 or 135 days, made more mistakes than controls in specific tests but that their relative learning rates were similar. ${ }^{209210}$ ? Again, however, these results and their statistical $\Rightarrow$ significance have been questioned. ${ }^{197}$ Present knowl- $\stackrel{9}{?}$ edge suggests that no acute behavioural alterations? are produced by concentrations of nitrous oxide $\overline{\bar{N}}$ below $8-12 \%$ or by less than $0.1 \%$ of halo- $\frac{\rho}{\sigma}$ thane. ${ }^{211-213}$

A finding that may or may not be relevant to the toxicity of anaesthetics is that among United States $\overrightarrow{0}$ doctors, whose overall suicide rate is $15 \%$ higher than that of the general population, ${ }^{214215}$ anaesthetists $\vec{\omega}$ are the second most suicidal subgroup (behind $\stackrel{\circ}{\circ}$ psychiatrists), with a rate three times that of the con- $\mathbb{D}$ trol group. ${ }^{216} 217$ This has been confirmed by Lew in $?$ a study of the causes of death among members of the $f$ American Society of Anesthesiologists, ${ }^{218}$ which has 00 named suicide as the major health risk among $r$ anaesthetists aged under $55^{219} 220$

\section{Diseases of the organs for the transformation and excretion of xenobiotics}

Hepatic diseases-Since the introduction of halo-ce thane in 1956, occasional cases of hepatic necrosis $\frac{2}{0}$ after its use as an anaesthetic have been $\vec{\theta}$ reported, ${ }^{221222}$ and repeated anaesthesia under halo- $\infty$ thane is now regarded as an aetiological factor that ${ }^{-}$ cannot be ignored. ${ }^{223}$ Subanaesthetic doses of halothane, isoflurane, diethyl ether, fluoxene, enflurane, and nitrous oxide have been found by some authors to cause hepatic alterations in animals, 224-227 whereas others have observed no such changes even $\stackrel{\unrhd}{\circledR}$ after lengthy or intense exposure ${ }^{228-230}$; controversy $\overrightarrow{\vec{A}}$ on this point continues. ${ }^{197231232}$ In operating theatre staff temporary rises in hepatic transaminase $\bar{P}$ levels have been reported, ${ }^{233}$ and also jaundice ${ }^{234}$ and hepatic cirrhosis, ${ }^{235}$ whereas in the United States Cohen $e t$ al found that the incidence of hepatic dis- $\frac{\mathbb{D}}{\square}$ eases was above average among female operating theatre staff ${ }^{236}$ and dentists using general anaesthesia 3 three hours a week or more. ${ }^{237}$ An increase in the frequency of hepatic diseases has also been observed among anaesthetists in Czechoslovakia ${ }^{238}$ and England and Wales. ${ }^{239}$

Kidney disease - Certain epidemiological studies $\frac{T}{0}$ have reported a higher than average rate of kidney disease among anaesthetists, women o especially 216236 238; Chang et al observed ultra- $N$ structural changes in the kidneys of laboratory ani- $N$ mals chronically exposed to low levels of $\mathrm{\omega}$ halothane $\mathrm{240}^{24}$ and Dahlgren found moderate temporary alterations of kidney function in Swedish health workers exposed to methoxyflurane. ${ }^{241}$

Faulty cell replication

Abortion and congenital malformation-In Vaisman's report attention was drawn to the high rate of abor- 
tions among women working in operating theatres in the Soviet Union. ${ }^{195}$ The same phenomenon was subsequently observed by Askrog and Harvald in Denmark ${ }^{242}$ and was confirmed by Cohen et al in the United States and Canada, ${ }^{236}$ where the abortion rate among pregnant women working in operating theatres was $17 \cdot 1 \%$ whereas that of other pregnant hospital workers was only $8.9 \%$. Other investigators have reached similar conclusions, ${ }^{238243244}$ though there have also been contradictory reports in which no increase in the spontaneous abortion rate was observed among doctors and nurses exposed to anaesthetic gases. ${ }^{245} 246$ Of the various dangers attributed to chronic exposure to traces of anaesthetic gases, the risk of abortion among women working in surgical departments is the only one recognised by the United Kingdom Department of Health and Social Security. ${ }^{247}$

A more surprising finding has been that abortions are twice as common among the wives of United States dentists administering general anaesthesia at least three hours a week as among the wives of those who use only local anaesthesia $(18 \% v 9 \%),{ }^{237}$ though Askrog and Harvald had already reported a similar phenomenon among the wives of Danish anaesthetists. ${ }^{242}$ This suggests that anaesthetic gases may affect spermatogenesis, and such alterations have indeed been observed in animals, ${ }^{248-251}$ but Wryobek et al found no changes in either the morphology or the concentration of spermatozoa produced by anaesthetists working in three San Francisco hospitals (though the modern gas extraction systems in these centres may have meant that these anaesthetists enjoyed better than average protection). ${ }^{252}$

Several studies have reported that women exposed to anaesthetic gases during gestation run a greater than average risk of giving birth to children with congenital malformations. ${ }^{236253-256}$ Tomlin found that the central nervous system and musculoskeletal system were especially affected by this abnormal incidence of malformations, ${ }^{244}$ whereas Pharaoh et al observed higher than. average frequencies of congenital cardiovascular malformations and stillborn births and a smaller average size among live newborn babies. ${ }^{245}$ Baltzar, however, found no such differences. ${ }^{257}$ The validity of many of these studies 237242244256257 has in any case been questioned $^{258-262}$ on the grounds that most were carried out using retrospective postal questionnaires. Ferstanding, ${ }^{260}$ Axelsson and Rylander, ${ }^{261}$ and Tannenbaum and Goldberg ${ }^{262}$ have been especially critical, pointing out numerous methodological flaws such as the lack of criteria for exposure or outcome, poor survey response rates, selection bias, lack of validation of outcome, recall bias, and lack of control of potentially confounding variables. ${ }^{262}$ These critics emphasise the need to carry out suitably designed prospective studies to determine whether or not exposure to trace concentrations of anaesthetic gases entails a real risk of abortion or congenital malformation.

Chronic exposure to anaesthetic concentrations of nitrous oxide or halothane has been reported to increase the resorption and congenital skeletal malformation rates among rats exposed during gestation ${ }^{263-267}$ or to reduce the weight and length of hamster fetuses, ${ }^{268}$ but no such effects have been observed at subanaesthetic levels. ${ }^{267269-271}$ Neither have changes been observed in the fertility of animals exposed to subanaesthetic doses, ${ }^{248269272}$ or in exposed chick embryos. ${ }^{273-280}$ Mutagenic effects on bacteria have been observed by some 281282 but not by others. ${ }^{283284}$ To sum up, there is at present no conclusive experimental evidence that chronic exposure to traces of anaesthetic gases - or even short exposure to high concentrations ${ }^{285}$ - has any adverse effects on gestation in animals.

Malignancies-Chloroform ${ }^{286} 287$ and trichloroethylene $^{238}$ have been found to be potentially carcinogenic (causing hepatic carcinomas and kidney tumours) for experimental animals exposed to large doses introduced by mechanisms different from those involved in the occupational exposure of man. With the exception of a study by Corbett, ${ }^{288}$ however, the results of which he was unable to reproduce ${ }^{289}$ there is no experimental evidence that low concentrations of halothane, nitrous oxide, enflurane, isoflurane, or methoxyflurane are carcinogenic. ${ }^{290-294}$

Bruce et al detected an abnormally high rate of mortality from lymphoid and reticuloendothelial tumours among anaesthetists during the period $1947-66,{ }^{216}$ but a subsequent study failed to confirm any relation ${ }^{217}$; Cohen $e t$ al observed a greater incidence of cancer among female anaesthetists in their nationwide study ${ }^{236}$ but found no difference between exposed and unexposed subjects in their study of dentists ${ }^{237}$; and although Corbett et al reported an above average cancer rate among anaesthetic nurses in Michigan, ${ }^{288}$ serious doubts have been raised as to the validity of both this study and Cohen's. 258259 The suggestion that anaesthetic gases may act as transplacental carcinogens is not supported by the studies of Knill-Jones et al $^{\mathbf{2 4 3}}$ and Pharaoh et al $^{245}$ in which the incidence of cancer is no greater among the children of female anaesthetists in England and Wales than among those of other women, though a difference between the two groups has been claimed by Tomlin. ${ }^{244}$ In view of these studies it cannot be concluded that there is a risk of cancer from chronic exposure to traces of anaesthetic gases. 
Other risks, and preventive measures

Irritation of the respiratory tract has been reported after chronic inhalation of ether, and laryngitis and attacks of asthma after exposure to halothane and enflurane respectively. ${ }^{295}$ Personnel long exposed to nitrous oxide have been reported to suffer neuropathies ${ }^{296-298}$ recently shown to be caused by the ability of nitrous oxide to oxidise vitamin $\mathbf{B}_{12}$, thus impeding the synthesis of methionine, folate, and thiamine. ${ }^{299-303}$

To prevent abnormalities caused by exposure to anaesthetic gases it is necessary to make anaesthetic and surgical staff aware of the risks and to urge the introduction of efficient gas extraction systems (levels of 130-7000 ppm of nitrous oxide and 10-85 ppm of halothane have been detected in the region where the anaesthetist breathes). ${ }^{304-306}$ Good practice codes should be adopted to reduce atmospheric pollution, routine inspections of equipment should be carried out, and routine checks on pollution levels in the affected areas and personnel should be performed. In the United States, where (without counting surgeons, dental staff, and vets, whose exposure is intermittent and variable) about 50000 people, $35 \%$ of them women, are occupationally exposed to anaesthetic gases (anaesthetists, anaesthetists's nurses, operating theatre nurses, and technicians), ${ }^{305}$ hospital regulations limit pollution in operating theatres to $25 \mathrm{ppm}$ of nitrous oxide and 1-2 ppm of halogenated agents. $^{307}$

\section{Drug addiction and psychic problems}

The risk of health workers becoming addicted to drugs arises because of the stress and anxiety to which they are subjected at times and because of the ready availability of suitable drugs. ${ }^{308}$ It is quite common for attempts to be made to overcome the pressures of overwork, stress, and affective strain by excessive resort to stimulants, whose use may alternate with excessive consumption of coffee or tobacco and the use of sleeping pills, alcohol, or other drugs. Several studies have confirmed that alcoholism, drug addiction, and depression are more common among doctors than among the general population, ${ }^{309-315}$ as are visits to the psychiatrist. ${ }^{316}$ For example, of the 5925 patients admitted to the psychiatric wards of the Mayo Clinic between 1956 and 1963, 93 were doctors (one in every 64 admissions), ${ }^{317}$ and in $59 \%$ of these cases the cause was either alcoholism $(\mathbf{1 6 \cdot 6 \% )}$ ) or drug addiction (34.4\%). Almost all these patients had used drink or drugs as a defence against acute anxiety. Similar findings were reported by Murray after examining admissions to psychiatric centres in Scotland ${ }^{318}$ : there were significantly higher than average rates of alcoholism, drug addiction, functional neurotic depression, and affective psychosis among $\frac{\pi}{\infty}$ doctors. Perhaps because of the high prevalence of $?$ depression, suicides are two to three times more com- $\vec{\Rightarrow}$ mon among doctors-psychiatrists especially ${ }^{318}$ - क ? than among the general population. ${ }^{313319-321}$ Mar- 응 ital and sexual dissatisfaction is also more prevalent $\frac{\bar{\sigma}}{\overline{0}}$ than among non-doctors, ${ }^{316322323}$ though the divorce rate is no higher than average. ${ }^{324-326} \mathbb{\mathscr { Q }}$

Work, which as a channel for the fulfilment of the individual may favour his or her psychic wellbeing, $\vec{O}$ may also prove psychically deleterious owing to the individual's own traits (personality, social conflicts, $\vec{\omega}$ etc), to the working environment (group relations), to $\stackrel{\odot}{\triangle}$ the nature of the work itself (disagreeable or alien- $\mathbb{\Phi}$ ating jobs, overfast workpace, excessive workloads, changes of shift), or to promotion.

\section{CHANGES OF SHIFT}

Changes of shift originate personal, family, and social $\stackrel{\circ}{\circ}$ problems. ${ }^{327}$ The resulting lack of synchronisation between exogenous stimuli ${ }^{328}$ (the periodic variation $\vec{\imath}$ of light, sound, heat, and atmospheric ionisation) and endogenous clocks ${ }^{329} 330$ gives rise to disorders due to dysrhythmia. In such cases the human organism, $\stackrel{\mathscr{\rho}}{\rightarrow}$ which is programmed for daytime activity, receives $\vec{\emptyset}$ stimuli opposed to its physiological requirements, the $\stackrel{\infty}{v}$ consequence being a characteristic disorder featuring insomnia, irritability, dyspepsia, spacial and temporal disorientation, and eventual corticosuprarenal exhaustion. ${ }^{331}$ Night work goes against the genetic, professional, and social characteristics of the human $\frac{\mathscr{Q}}{\mathbb{2}}$ species. Working while in a state of nocturnal "dis- $\varrho$ activation" requires double effort and hence produces $\overrightarrow{\bar{O}}$ greater fatigue than day work, and this fatigue is incompletely eliminated because daytime sleep is less restful than night sleep. This state of chronic fatigue is exemplified by the slowing down of motor responses to optical and acoustic stimuli and by decreased $\rightrightarrows$ efficiency at work. Digestive dysrhythmia is also observed, and there is greater dependence on tobacco $\frac{3}{9}$ and alcohol among night workers than among dayo workers.

The family life of the night worker is likewise upset, 음 since unless the hours kept by the rest of the family $>$ are made to fit in with his he himself must either fit in with theirs or live apart. Socially, night work results in greater insularity (nightworkers have fewer friends). and less participation in group activities (sports, $N$ union or political work, or cultural pursuits), though N it is also true that morning and afternoon shifts like-0 wise have their social disadvantages. Thus the morn-e ing shift allows the midday meal to be shared with the family and leaves time for other family and social $\stackrel{\infty}{?}$ activities, but since it begins so early may also prove 0 fatiguing. The afternoon shift prevents social life, $\stackrel{0}{\circ}$ since contact with the children is limited and there are 
no evenings out, but sleeping hours are normal and workers with alternating shifts regard it as allowing lost sleep to be made up. It is the night shift that causes most problems due to its consequences for family life and social activity. ${ }^{332}$

Emotional stress is one of the main health hazards for hospital personnel,,$^{333-335}$ especially for the student or young graduate nurse, and derives from contact with the dying, with seriously ill children, and with sorrowful, anxious, and suicidal patients. Working in intensive care units also gives rise to situations that, depending on the personality of the individual, may cause pathological psychic disorders. ${ }^{336} 337$ In this context the relation between doctor and patient is passive, with the doctor and nurse being under the constant pressure of having continually to take instant decisions that are critical for the patients' lives. This highly stressful combination of great responsibility and continuous attention to patients' needs, which is further exacerbated by a work pattern that does not allow relaxation during breaks and leisure periods, ends up by producing exhaustion and reduced operational capacity. ${ }^{336} 338339$ Signs of stress among intensive care unit workers include psychosomatic disorders (mainly affecting the digestive system), anomalous social reactions, various types of neuroses and depression, and even dereliction of duty. ${ }^{340}$ Psychopathological stress likewise tends to increase when health work becomes monotonous, boring, and "meaningless" while retaining its demanding nature. In all these stressful circumstances, however, the effect on the health worker depends largely on his attitude to the situation and on his resources for coping with it. ${ }^{337} 341$

\section{Assault}

Human life undoubtedly includes a degree of aggressive conduct, whether this be innate or acquired. The necessity of continual adaptation to a changing environment forces such conduct on us, especially in a society as competitive as ours. In this section, however, we shall limit our considerations to the urge to harm some person (or some object that represents or replaces that person), the harm caused being the sole aim of the aggressive act. Innate aggressive behaviour needs no stimulus, but there also exist socially acquired forms of aggression that are triggered by external stimuli such as frustration. The patient and his relatives should therefore never be frustrated, since they may become aggressive. ${ }^{342-345}$

Frustration may be produced when the behaviour of health workers is unfitting or is not what is expected, in short when they forget their role. Health care involves a social group comprising the health worker, the patient, and the latter's relatives and friends. To paraphrase Berard and Gubler, sometimes it achieves its purpose, the curing of the disease; generally it manages to provide relief; and it always provides assuagement. ${ }^{346}$ Each member of the group has his own status and accompanies the execution of a particular function with a behaviour that is expected by the others. Each status and role in the group has its complement: husband and wife, father and son, health worker and patient. The roles of the health worker and the patient are defined by the ambient culture and certain aspects are even regulated by law. ${ }^{347}$ The role of the patient is characterised both by rights such as exemption from his responsibilities and the right to receive aid, and by obligations such as his obligation to wish for his own recovery and to cooperate in his treatment. ${ }^{348}$ The status and role of the health worker are characterised by impartiality (giving each patient the attention required by the gravity of his illness), by confidentiality (using the patient's body and the information he knows regarding the patient solely for the patient's cure), by affective neutrality (avoiding involvement in the patient's affective problems), by disinterested altruism, and by technical and scientific competence. ${ }^{41}$ Criticism of the health worker's behaviour will come from the patient's relatives and friends, the commonest criticism being that little time is devoted to Social Security patients. ${ }^{349}$ The patient should be convinced that a diagnosis has been attained or at least that everything possible is being done to attain it. The harmonious course of the relation between doctor and patient, each with his status and role, is fundamental for achieving the objective, health. ${ }^{350-352}$ If disrupted the results may be pathogenic not only for the patient but, paradoxically, for the doctor also. ${ }^{353}$

For the doctor, the pathogenic consequences of a breakdown in his relation with the patient may be physical (injuries), anatomopathological (heart attacks), or functional or psychosomatic (ulcers). The sources of the patient's aggressive conduct may be classified in three categories: those arising in the context of his relation with the doctor, those arising in his own family and working environment, and a residual group of other social sources. Aggression may take the form of physical assault or verbal attacks and be received either by the health worker himself or by his family or possessions. Verbal assault is undoubtedly the most common but cases of physical attack are by no means rare and are occasionally reported by the daily newspapers.

When faced with patients known to be mentally ill, awareness of the possibility of apparently unmotivated fits of violence puts the doctor on his guard. The most dangerous are the paranoics, 
especially the hypochondriacs convinced that they are suffering from a serious illness because the doctor is treating them badly (there is usually another health worker encouraging such patients). Female erotomaniacs convinced that only the doctor's shyness prevents his declaring his love for them generally limit themselves to verbal assault but the doctor should avoid being left alone with them. Hysterical mythomaniacs put about false rumours and reports whose truth they believe in once they have uttered them. Excited schizophrenics and hypomaniacs can also be aggressive (the latter-usually verbally-on being told the truth about their condition, which it is sometimes wiser to keep to oneself). Assaults by drug addicts and sadists may likewise be expected. Assaults by sane patients are much more dangerous because they are unexpected; and are much more important because their unexpectedness means that the doctor was unaware of how he had frustrated the patient. ${ }^{354}$

Finally, a different type of "assault" to which health workers are exposed is their being sued for malpractice by their patients. ${ }^{355-358}$ Though none would wish to deny patients this right, it should be pointed out that widespread abuse of its exercise may prove detrimental to health care by inducing health workers to practise medicine on the defensive, with greater importance being given to what it is legally safe for the doctor to do than to what is beneficial for the patient. ${ }^{359}$ Paradoxically, there are grounds for thinking that the spate of malpractice cases currently disturbing United States doctors' peace of mind is in part due to the very success of modern medicine: the fact that the act of healing is now a commonplace has resulted in a tendency for any failure to be immediately attributed to negligence on the doctor's part rather than to the intrinsic limitations of his art.

\section{References}

The following are the most important of the references cited in the text. A complete list may be obtained from the author on request.

1 Gestal JJ. Occupational hazards in hospitals: risk of infection. Br J Ind Med 1987;44:435-42.

2 Freeman NT, Whitehead J. Introduction to safety in the chemical laboratory. London: Academic Press, 1982.

5 Link LJ. Electrical safety in hospitals, a current review of principles and practices. Eire, Pennsylvania: American Sterilizer Company, 1976.
30 Braestrup CB, Vikteriof $\mathrm{KJ}$. Manuel de radioprotection dans les hospitaux et en practique génerale. Genéve: Organisation Mondiale de la Santé, 1974:vois I, II, III.

34 Department of Health and Social Security. Guidance on the safe $\overrightarrow{\vec{G}}$ use of lasers in medical practice. London: HMSO, 1984.

37 Steward T. Problems caused by the continuous use of visual display units. Lighting Research Technology 1980;1:26-36.

44 Fisher AA. Contact dermatitis in medical and surgical person- $\overline{\bar{\omega}}$ nel. In: Maitach HI, Gellin GA, eds. Occupational and industrial dermatology. London: Year Book Medical Publishers, $\varrho$ 1982:219-28.

54 Organizacion Mundial de la Salud. Limites recomendados por razones de salud en la exposicion profesional a determinados $\vec{O}$ solventes organicos. Ginebra: OMS Ser inf técn 1982;664: 9-43.

76 Organizacion Mundial de la Salud. Limites de exposicion profesional que se recomiendan por razones de salud: substancias $\bigcirc$ irritantes de las vias respiratorias. Ginebra: OMS Ser inf técn 1984;707:39-76.

77 Gonzalez Ferradas E. Formaldehido: toxicologia e impacto ambi- $\underset{f}{+}$ ental. Madrid: Ed Mapfre, 1986.

78 Gibson JE Formaldehyde toxicity. London: Hemisphere Publishing Corporation, McGraw-Hill International Book Com- $\vec{\circ}$ pany, 1983.

136 Acheson ED, Gardner MJ, Pannett B, Barnes HR, Osmond C, Taylor CP. Formaldehyde in the British chemical industry. Lancet 1984;ii:611-6.

143 Gennart JP, Dutrieux M, Lauwerys R. La toxicité de l'oxideç d'éthyléne: revue de la littérature. Archives des Maladies Professionelles de Medicine du Travail et de Securité Sociale 1983;4:269-74.

189 Riesgos y prevencion en el manejo de soluciones citostaticas. Malaga: Sociedad Española de Higiene y Medicina Preventiva. Hospitalaria, 1985:2. (Serie documentos tecnicos.)

197 Ferstanfing LL. Trace concentrations of anesthetic gases: a critical review of their disease potential. Anesth Analg 1978;57:328-45.

198 Edling C. Anesthetic gases as an occupational hazard: a review. Scand J Work Environ Health 1980;6:85-93.

262 Tannenbaum TN, Goldberg RJ. Exposure to anesthetic gases and reproductive outcome: a review of the epidemiologic lite- $\bar{O}$ rature. J Occup Med 1985;9:659-68.

311 Modlin HC, Montes A. Narcotics addiction in physicians. Am J Psychiatry 1964;121:358-65.

313 A'Brook MF, Hailstone JD, McLaughlan IEJ. Psychiatric illness in the medical profession. Br J Psychiatry 1967;113: 1013-23.

322 Scheiber SC. Emotional problems of physicians: I nature and extent of problems. Ariz Med 1977;34:323-5.

324 Fine C. Married to medicine: an intimate portrait of doctors' wives. New York: Atheneum, 1981.

332 Leonard R. Le travail de nuit et les horaries alternants. Paris: Université de Paris, 1982.

$335 \mathrm{McCue}$ JD. The effects of stress on physicians and their medical 음 practice. $N$ Engl J Med 1982;8:458-63. 343 Carthy JD, Ebling FJ. Historia natural de la agresion. México:

358 Ataz L. Los médicos y la responsabilidad civil. Madrid: Editorial N Montecorvo, 1985 